\title{
Overlap Syndromes: Exploring the Genetic Underpinnings
}

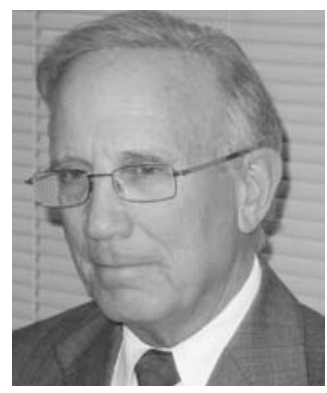

In this issue of The Journal, Mohammed, et al ${ }^{l}$ describe a group of patients with erosive arthritis who have features of Sjogren's syndrome (SS) sufficient to meet American-European consensus criteria ${ }^{2}$. The same patients also meet 1987 American College of Rheumatology (ACR) criteria for rheumatoid arthritis (RA) ${ }^{3}$. The initial reaction to this description might be to dismiss the importance of the relationship because the patients with arthritis can be labelled as RA with Secondary SS. But what role do classification criteria play?

Because of the lack of a single gold standard in most rheumatic diseases, including SS, development of criteria for diagnosis or classification has been of continuing interest to rheumatologists.The main purpose of classification criteria is to standardize clinical definitions for use in research studies ${ }^{4}$. Standardized definitions are needed to allow comparison of studies from different centers. Included in classification criteria will be findings that distinguish a given disease from another similar illness. But this requires selection of criteria with higher specificity, and lower sensitivity. For this reason, classification criteria differ from diagnostic criteria.

Classification criteria are established to clearly define groups. Diagnostic criteria are meant for application in an individual patient. The individual may have a given disease, even if he does not meet the classification criteria for the disease.

The European-American consensus criteria were meant for the classification of SS. They were not established for the purpose of diagnosis, even though many investigators use them this way. To be sure, consensus criteria work well for the establishment of diagnosis, but there may well be cases that satisfy the clinician without meeting criteria. We must be careful not to be blinded by the use of classification criteria for diagnosis, as this can prevent us from studying the exceptions that shed light on disease understanding.

Mohammed, et al further our insight into the role that immune response genes and autoantibody profile play in disease expression. In 2008, Iwamoto, et al opened this discussion in The Journal by describing a group of patients with SS and non-erosive arthritis who also had anticyclic citrullinated peptide antibodies (anti-CCP) $)^{5}$. The cohort they presented had nonerosive arthritis, but the presence of anti-CCP was seen more prominently in these patients than in the remaining SS patients without arthritis.

Mohammed, et al have moved this perspective along, demonstrating that the common epitope associates with expression of anti-CCP antibodies and erosive articular inflammation, that DRB $1 * 0301$ associates with production of anti-Ro antibodies and development of SS, and that both these processes can occur in the same patient. Further, there was some modification in the patients with arthritis that made them somewhat different from simple rheumatoids. The arthritis group had no deformities, and a smaller percentage had erosions. They reported rash with the same frequency as the patients with SS, as well as peripheral sensory neuropathy and Raynaud's phenomenon.

Is this a perspective unique to SS? No it is not. Recent studies have shown that the shared epitope containing HLA-DRB1 alleles is associated with the presence of anti-CCP antibodies in RA, and not with anti-CCP negative $\mathrm{RA}^{6}$. Further, only the progression of early arthritis into $\mathrm{CCP}$ positive erosive arthritis can be predicted by the presence of the shared epitope ${ }^{7}$. With univariate analysis, the shared epitope does not seem to correlate with the development of anti-CCP negative RA, even if rheumatoid factor is present $^{8}$.

What will we see if the shared epitope, with the production of anti-CCP, is expressed in other rheumatic diseases? In patients with systemic lupus erythematosus, HLA-DRB1 genes with the shared epitope result in anti-CCP leading to erosions ${ }^{9}$. Such SLE patients have overlap features of RA ("rhupus"), satisfying ACR classification criteria for both SLE and RA. Anti-CCP antibodies exert the same disease

See Association of severe inflammatory polyarthritis in primary Sjögren's syndrome, page 1937 Personal non-commercial use only. The Journal of Rheumatology Copyright @ (2009. All rights reserved. 
expression when found in seronegative diseases. In a cohort of patients with psoriatic arthritis 5.6\% were anti-CCP antibody positive. These patients were significantly associated with the HLA-DRB1 shared epitope, erosive disease, increased number of swollen joints, and increased use of disease modifying antirheumatic drugs ${ }^{10}$.

The perspective raised here by Mohammed, et al is that connective disease expression is multifactorial, dependent upon genetic underpinnings and autoantibody profile. The ability to consider disease overlap in this manner enhances our understanding of autoimmune disease pathogenesis. SS itself, aside from the myriad systemic manifestations documented for the disease, can develop overlap features suggestive of limited scleroderma of the CREST variety and primary biliary cirrhosis. Anticentromere antibodies in SS identify a subgroup with many overlap features ${ }^{11}$.

We have a long way to go before we can understand why SS overlaps with these specific diseases and not others. The case control study in this issue paves the way for understanding how such overlap expression might occur by working with the previously ignored association of erosive arthritis and SS and studying immune response genes and effector antibodies that are known to us.

ARTHUR A.M. BOOKMAN, MD, FRCPC, University Health Network, Toronto Western Hospital, 399 Bathurst Street, Room 1E424, Toronto, Ontario M5T 2S8, Canada

Address correspondence to Dr. Bookman;

E-mail: arthur.bookman@uhn.on.ca

\section{REFERENCES}

1. Mohammed K, Pope J, Le Riche N, Brintnell W, Cairns E, Coles R, et al. Association of severe inflammatory polyarthritis in primary Sjögren's syndrome: Clinical, serologic, and HLA analysis. J Rheumatol 2009;36:1937-42.
2. Vitali C, Bombardieri S, Jonsson R, Moutsopoulos HM, Alexander EL, Carsons SE, et al. Consensus report. Classification criteria for Sjögren's syndrome: a revised version of the European criteria proposed by the American-European Consensus Group. Ann Rheum Dis 2002;61:554-8.

3. Arnett FC, Edworthy SM, Bloch DA, McShane DJ, Fries JF, Cooper NS, et al. The American Rheumatism Association 1987 Revised Criteria for the classification of rheumatoid arthritis. Arthritis Rheum 1988;31:315-24.

4. Hunder GG. The use and misuse of classification and diagnostic criteria for complex diseases. Ann Intern Med 1998;29:417-8.

5. Iwamoto N, Kawakami A, Tamai M, Fujikawa A, Arima K, Karamaki T, et al. Determination of the subset of sjögren's syndrome with articular manifestations by anticyclic citrullinated peptide antibodies. J Rheumatol 2009;36:113-6.

6. Huizinga TW, Amos CI, van der Helm-van Mil AH, Chen W, van Gaalen FA, Jawaheer D, et al. Refining the complex rheumatoid arthritis phenotype based on specificity of the HLA-DRB1 shared epitope for antibodies to citrullinated proteins. Arthritis Rheum 2005;52:3433-8.

7. El-Gabalawy HS, Goldbach-Mansky R, Smith II D, Arayssi T, Bale S, Gulko P. Association of HLA alleles and clinical features in patients with synovitis of recent onset. Arthritis Rheum 1999;42:1696-705.

9. van der Helm-van Mil AHM, Verpoort KN, Breedveld FC, Huizinga TWJ, Toes REM, and de Vries RRP. The HLA-DRB1 shared epitope alleles are primarily a risk factor for anti-cyclic citrullinated peptide antibodies and are not an independent risk factor for development of rheumatoid arthritis. Arthritis Rheum 2006;54:1117-21.

9. Chan MT, Owen P, Dunphy J, Cox B, Carmichael C, Korendowych E. Associations of erosive arthritis with anti-cyclic citrullinated peptide antibodies and MHC class II alleles in systemic lupus erythematosus. J Rheumatol 2008;35:77-83.

10. Korendowych E, Owen P, Ravindran J, Carmichael C, McHugh N. The clinical and genetic associations of anti-cyclic citrullinated peptide antibodies in psoriatic arthritis. Rheumatology 2005;44:1056-60.

11. Salliot C, Gottenberg J, Bengoufa D, Desmoulins F, Miceli-Richard C, Mariette X. Anticentromere antibodies identify patients with Sjögren's syndrome and autoimmune overlap syndrome. J Rheumatol 2007;34:2253-8.

J Rheumatol 2009;36:1856-7; doi:10.3899/jrheum.090733 


\section{Correction}

Bookman AAM. Overlap syndromes: Exploring the genetic underpinnings [editorial]. J Rheumatol 2009;36:1856-7. References 6 to 11 should appear as follows. This correction applies to the printed edition only. We regret the error.

6. Huizinga TW, Amos CI, van der Helm-van Mil AH, Chen W, van Gaalen FA, Jawaheer D, et al. Refining the complex rheumatoid arthritis phenotype based on specificity of the HLA-DRB1 shared epitope for antibodies to citrullinated proteins. Arthritis Rheum 2005;52:3433-8.

7. El-Gabalawy HS, Goldbach-Mansky R, Smith II D, Arayssi T, Bale $\mathrm{S}$, Gulko P. Association of HLA alleles and clinical features in patients with synovitis of recent onset. Arthritis Rheum 1999;42:1696-705.

8. van der Helm-van Mil AHM, Verpoort KN, Breedveld FC, Huizinga TWJ, Toes REM, and de Vries RRP. The HLA-DRB1 shared epitope alleles are primarily a risk factor for anti-cyclic citrullinated peptide antibodies and are not an independent risk factor for development of rheumatoid arthritis. Arthritis Rheum 2006;54:1117-21.

9. Chan MT, Owen P, Dunphy J, Cox B, Carmichael C, Korendowych E. Associations of erosive arthritis with anti-cyclic citrullinated peptide antibodies and mhc class ii Alleles in systemic lupus erythematosus. J Rheumatol 2008;35:77-83.

10. Korendowych E, Owen P, Ravindran J, Carmichael C, McHugh N. The clinical and genetic associations of anti-cyclic citrullinated peptide antibodies in psoriatic arthritis. Rheumatology 2005;44:1056-60.

11. Salliot C, Gottenberg J, Bengoufa D, Desmoulins F, Miceli-Richard $\mathrm{C}$, Mariette X. Anticentromere antibodies identify patients with Sjögren's syndrome and autoimmune overlap syndrome. J Rheumatol 2007;34:2253-8.

doi:10.3899/jrheum.090733C1 